\title{
Effects of low-intensity pulsed ultrasound on injured skeletal muscle
}

\author{
Camila S. Montalti ${ }^{1}$, Natália V. C. K. L. Souza ${ }^{1}$, Natália C. Rodrigues ${ }^{2}$, \\ Kelly R. Fernandes ${ }^{1}$, Renata L. Toma ${ }^{1}$, Ana C. M. Renno ${ }^{1}$
}

\begin{abstract}
Background: Low-intensity pulsed ultrasound (LIPUS) has been shown to stimulate tissue metabolism and accelerate muscle healing. However, the optimal parameters in the use of LIPUS are still not clear. Objective: The aim of this study was to analyze the effects of LIPUS on muscle healing in rats subjected to a cryolesion. Method: Twenty rats were divided into the following groups: an injured control group (CG) and an injured treated group (TG). Both groups were divided into 2 sub-groups $(n=5$ each) that were sacrificed 7 and 13 days post-surgery. Treatments were started 24 hours after the surgical procedure and consisted of 3 or 6 sessions. After euthanasia, the muscles were submitted to standard histological procedures. Results: Qualitative analyses were based on morphological assessments of the muscle. The histopathological analysis on day 7 revealed that the muscles in the CG and the TG presented an intense inflammatory infiltrate, a large necrotic area and a disorganized tissue structure. After 13 days, both the CG and the TG had granulation tissue and newly formed fibers. The TG presented a more organized tissue structure. The quantitative analysis of collagen indicated similar findings among the groups, although the qualitative analysis revealed a better organization of collagen fibers in the TG at 13 days. The immunohistochemical analysis indicated that, at both time points, the expression of cyclooxygenase- 2 was upregulated in the TG compared to the CG. Conclusions: LIPUS used as a treatment for muscle injury induced a more organized tissue structure at the site of the injury and stimulated the expression of COX-2 and the formation of new muscle fibers.
\end{abstract}

Keywords: muscle tissue; muscle injury; cryolesion; muscle regeneration; low-intensity pulsed ultrasound.

\section{HOW TO CITE THIS ARTICLE}

Montalti CS, Souza NVCKL, Rodrigues NC, Fernandes KR, Toma RL, Renno ACM. Effects of low-intensity pulsed ultrasound on injured skeletal muscle. Braz J Phys Ther. 2013 July-Aug; 17(4):343-350. http://dx.doi.org/10.1590/S1413-35552012005000101

\section{- Introduction}

Skeletal muscle injuries are one of the most common lesions occurring in sports and daily activities, and the prevalence and incidence of these injuries are responsible for an increase in the high cost of therapy ${ }^{1-3}$. The healing of muscle tissue after an injury comprises a sequence of different steps, which lead to the restoration of the tissue architecture and function ${ }^{4}$. The first step is the inflammatory phase, which is characterized by the formation of a hematoma and an inflammatory cell reaction. This step is followed by the repair phase, which consists of the phagocytosis of the necrotic tissue, the regeneration of the myofibers and the production of a connective tissue scar. The final step of regeneration is the remodeling phase, which consists of the maturation of the regenerated myofibers and tissue reorganization ${ }^{2,5}$.

Although muscle tissue has the ability to regenerate by itself, depending on the extension of the lesion or in certain situations, such as poor vascularization, the regeneration occurs very slowly, resulting in muscle dysfunction, atrophy, contracture and pain ${ }^{2,4}$. In this context, there is a need to develop treatments that are able to accelerate muscle cell proliferation and prevent fibrosis during the healing process ${ }^{6}$.

Some therapies, such as ultrasound (US), are common modalities used for treating several skeletal muscle conditions ${ }^{2,6}$. Therapeutic US is a type of mechanical energy that is transmitted in the form of acoustic pressure waves and elicits thermal and nonthermal physiological modifications in the tissues ${ }^{7,8}$. It has been theorized that micromechanical strains, which are produced in biological tissues by such pressure waves, may result in biochemical events that accelerate tissue healing ${ }^{6}$. In muscle tissue, US can stimulate the proliferation of myogenic precursor cells, myogenic cells and fibrillar collagen ${ }^{3,6,7,9}$. Furthermore, the effects of US are related to an increase in the synthesis of proteins, such as matrix metalloproteinase 1 and collagenase ${ }^{7}$, and the production of prostaglandin E2 (PGE2) via 
the induction of cyclooxygenase-2 (COX-2 $)^{10}$, which then elevates the gene expression for bone sialoprotein (BSP), insulin-like growth factor-1 (IGF-1), osteocalcin (OC) and RunX2 ${ }^{11}$. In addition, the non-thermal effects, such as acoustic streaming and cavitation, lead to increases in cell membrane permeability and protein and collagen synthesis, post-injury inflammatory processes, the stimulation of new blood vessel formation and the acceleration of soft tissue healing ${ }^{2,7,12-15}$. In muscle tissues, US can stimulate the proliferation of myogenic precursor cells, myogenic cells and fibrillar collagen ${ }^{2,7,12-14}$. Piedade et al. ${ }^{2}$ found that US was able to stimulate myoregeneration and collagen deposition as well as accelerate the tissue regeneration process in an experimental model of lacerative gastrocnemius muscle lesion. Moreover, Shu et al. ${ }^{9}$ demonstrated that US at different doses $\left(0.25 \mathrm{~W} / \mathrm{cm}^{2}, 0.5 \mathrm{~W} / \mathrm{cm}^{2}\right.$ and $0.75 \mathrm{~W} / \mathrm{cm}^{2}$ ) was effective in treating muscle injuries.

Despite the positive effects of US on tissue regeneration, the mechanism by which such therapy acts on muscle tissues is not fully understood, and the use of US as a treatment modality is still controversial for many ${ }^{2,6}$. Moreover, the use of a wide range of doses by different authors and the lack of standardized experimental conditions make it difficult to compare the published results. Considering that some inflammatory mediators, such as prostaglandin and arachidonic acid products, play an important role during tissue repair, it is essential to evaluate the effects of US on cyclooxygenase- 2 expression during the process of muscle repair. Because US is widely used for accelerating the tissue healing process, the aim of this study was to evaluate by means of histopathological analysis and immunohistochemistry the temporal physiological modifications during the process of muscle healing in rats after the treatment with low-intensity pulsed ultrasound (LIPUS).

\section{Method}

\section{Animals}

Twenty Wistar male rats (12 weeks, weighing $300 \pm 20 \mathrm{~g}$ ) were used in the current study. The rats were maintained under a controlled temperature $\left(22 \pm 2^{\circ} \mathrm{C}\right)$, with light-dark periods of 12 hours, and with free access to water and a commercial diet. All of the animal handling and surgical procedures were strictly conducted according to the Guiding Principles for the Care and Use of Laboratory Animals. This study was approved by the Ethics Committee of the Universidade Federal de São Paulo (UNIFESP), Santos, SP, Brazil (Protocol number: 1456/10). The animals were randomly distributed into 2 groups: an injured control group (CG), injured animals without any treatment, and a LIPUS-treated group (TG), injured animals treated with LIPUS. Both groups were divided into 2 sub-groups ( $\mathrm{n}=5$ each), which were sacrificed at 2 different days post-surgery ( 7 or 13 days post-injury).

\section{Experimental design}

\section{Surgery}

The animals were subjected to anesthesia with xylazine $\left(\right.$ Syntec $^{\circledR}, 20 \mathrm{mg} / \mathrm{kg}$, IP) and ketamine (Agener ${ }^{\circledR}, 40 \mathrm{mg} / \mathrm{kg}$, IP), and exposed to a cryolesion of both the right and left TA muscles. The cryolesion consisted of two freeze-thaw cycles of the muscle in situ. Freezing was carried out by applying the flat end $(0.4 \times 0.4 \mathrm{~cm})$ of a piece of iron, pre-cooled in liquid nitrogen ( 30 seconds), to the surface of the proximal and distal third parts of the muscle and maintaining it in position for $10 \mathrm{~s}$ (twice). Once the muscles had thawed, the wounds were closed with polyamide threads (6-0), and thereafter, the animals were kept for several hours on a warm plate $\left(37^{\circ} \mathrm{C}\right)$ to prevent hypothermia.

\section{Treatments}

The treatments were started 24 hours post-surgery and were repeated every 48 hours for 3 or 6 treatment sessions, according to the group. LIPUS (Exogen Inc., Piscataway, NJ, USA), at $1.5 \mathrm{MHz}, 1: 4$ duty cycles, intensity SATA $30 \mathrm{~mW} / \mathrm{cm}^{2}$, and an ERA of $2.5 \mathrm{~cm}^{2}$, with $20 \mathrm{~min} / \mathrm{session}$, was used ${ }^{16}$. The irradiation was performed at one point above the injury area using a stationary mode application with gel as the coupling agent. On days 7 and 13 postinjury, the animals were sacrificed (with profound sedation and an overdose of ketamine and xylazine $(0.5 \mathrm{~mL}$ each $)$ to extract their tibialis anterior muscles.

\section{Histopathological analysis}

The muscles obtained from all of the experimental and control groups were washed immediately with saline and then fixed in 10\% buffered neutral formalin solution. After fixation, the muscle tissue was processed by embedding it in paraffin. The tissue was then sectioned (5 micrometers/section) and stained with hematoxylin and eosin (H\&E). The histopathological evaluation was carried out under a 
light microscope. The pathologist (DAR) was blinded to the treatments. The qualitative analysis considered any changes at the injury site, such as the presence of inflammation, granulation tissue, necrotic areas or any tissues undergoing hyperplastic, metaplastic and/or dysplastic growth, were and was conducted for each animal ${ }^{6}$.

\section{Collagen analysis}

The amount of collagen at the site of the injury was measured by the picrosirius-polarization method ${ }^{17}$. The histological sections were stained with picrosirius red, which under polarized light, permits the assessment of structural changes in the new muscle fibers. This method allows the performance of a qualitative and a quantitative evaluation of the muscle organization stage based on the birefringence of the collagen fiber bundles after staining with picrosirius and hematoxylin. The analysis was conducted using the Senarmont compensator method with $1 / 4$. Forty measurements were performed for each subgroup studied using monochromatic light and a Schott interference filter, $1=546 \mathrm{~nm}$. The resulting measurements in degrees were transformed to $\mathrm{nm}$ by multiplying the degrees by 3.03 . The total birefringence of the collagen fibers was measured after saturating with distilled water. To carry out the measurements along the axis of the tendon, the longitudinal axis of the collagen fibers was orientated at $45^{\circ}$ from the direction of propagation of the polarizing light. The measurements were made at different points in the central area of the muscle that corresponded to the lesion area.

\section{Immunohistochemistry}

Serial longitudinal muscle sections of $5 \mathrm{~mm}$ were deparaffinized in xylene and rehydrated in graded ethanol solutions, the sections were then pretreated in a microwave (Brastemp, SP, Brazil) with $10 \mathrm{mM}$ citric acid buffer $(\mathrm{pH}=6)$ for 3 cycles of 5 min each at $850 \mathrm{~W}$ for antigen retrieval. The specimen material was pre-incubated with $0.3 \%$ hydrogen peroxide in PBS for $5 \mathrm{~min}$ for the inactivation of endogenous peroxidase; the sections were then blocked with $5 \%$ normal goat serum in PBS solution for $10 \mathrm{~min}$. The specimens were then incubated with anti-COX-2 antibody (Santa Cruz Biotechnology, USA) at a concentration of 1:400. The incubation was carried out overnight at $4{ }^{\circ} \mathrm{C}$ in the refrigerator and followed by two washes in PBS for $10 \mathrm{~min}$. The sections were then incubated with biotin-conjugated secondary antibody (anti-rabbit IgG) (Vector Laboratories, Burlingame, CA, USA) at a concentration of 1:200 in
PBS for 1 hour. The sections were washed twice with PBS before the application of a preformed avidinbiotin complex conjugated to peroxidase (Vector Laboratories, Burlingame, CA, USA) for $45 \mathrm{~min}$. The bound complexes were visualized with the application of a $0.05 \%$ solution of 3-3'-diaminobenzidine and counterstained with Harris hematoxylin. For the controls in the antibody studies, the serial sections were treated with rabbit IgG (Vector Laboratories, Burlingame, CA, USA) at a concentration of 1:200 in place of the primary antibody. Additionally, internal positive controls were performed with each staining bath.

The immunohistochemical data were evaluated by an experienced pathologist (DAR) under subjective morphologic analysis as established in previous studies conducted by our group ${ }^{6}$.

\section{Statistical analysis}

The results were reported as the means and standard deviations. The data from picrosirius analysis were evaluated using a two-way analysis of variance (ANOVA) to compare changes among the groups, followed by the post-hoc Student-NewmanKeuls method. The statistical significance level was defined as $p<0.05$. The statistical evaluation was carried out using STATISTICA 7.

\section{Results}

\section{Histopathological findings}

Seven days post-surgery, the histopathological analysis of the CG revealed severe morphological modifications, such as destroyed zones with interstitial edema and the presence of critical multifocal inflammatory cell recruitment, characterizing an acute extensive myofibrillar degeneration (Figure 1A). The TG also had destroyed zones and interstitial edema; however, a more abundant inflammatory infiltrate was observed (Figure 1B). Furthermore, granulation tissue was observed in the area of the injury in some specimens of the TG.

After 13 days post-surgery, granulation tissue and newly formed muscle fibers could be observed in both groups (Figures 2A and 2B). However, the TG displayed better tissue structure organization compared to the CG.

\section{Collagen analysis}

Figure 3 illustrates the qualitative analysis of the collagen. The CG had a more disorganized structure 


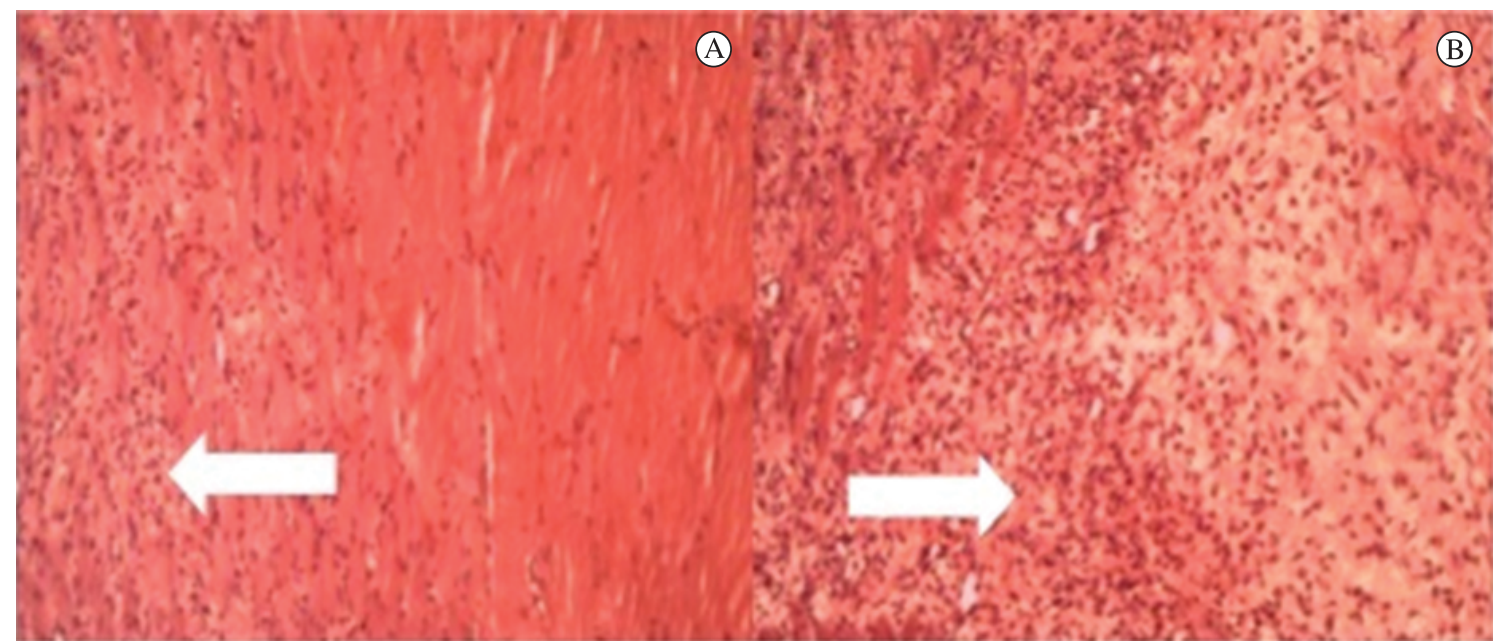

Figure 1. (A) control group (CG) and (B) treated group (TG) 7 days post-surgery. Arrow indicates inflammatory infiltrate. H.E. stain. 40X.

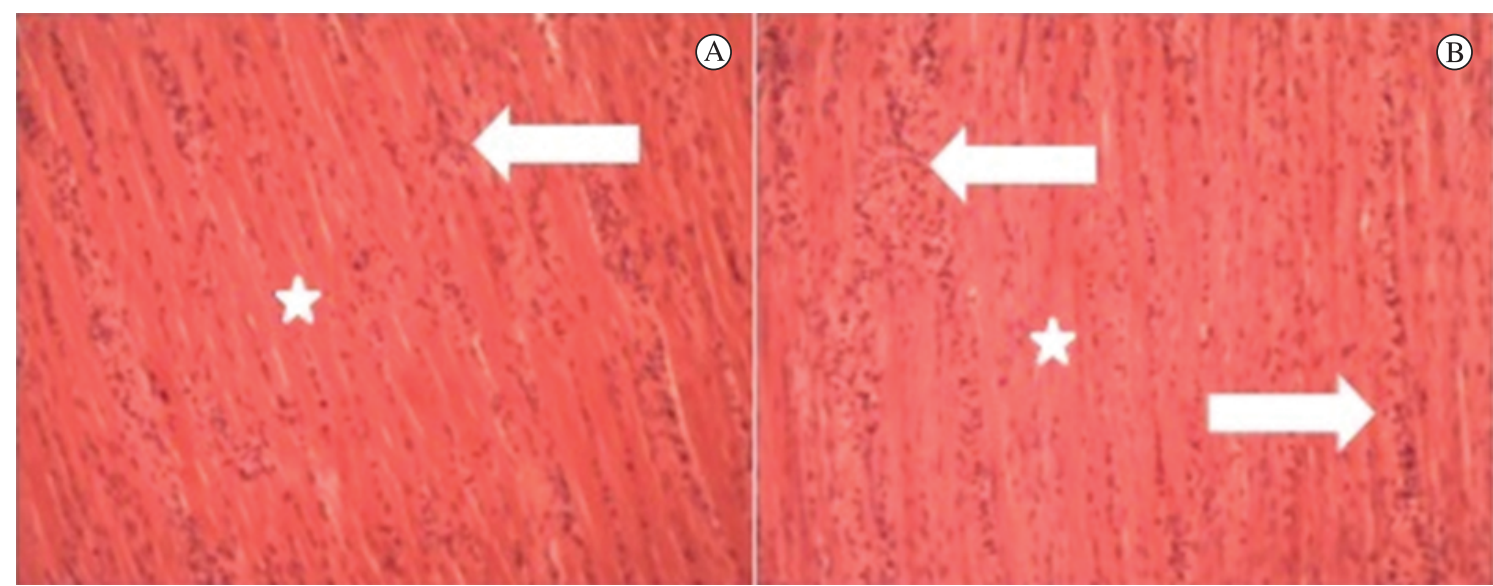

Figure 2. (A) control group (CG) and (B) treated group (TG) 13 days post-surgery. Arrow indicates granulation tissue and asterisks indicate new muscle fibers. (40X).

of collagen fiber deposition compared to the TG at 7 days post-surgery (Figures $3 \mathrm{~A}$ and 3B). The same findings were observed 13 days post-surgery. The TG had a greater amount of collagen fiber deposition with a better alignment among the fibers compared to the CG (Figures 3C and 3D). However, the quantitative analysis did not reveal significant differences in the collagen fiber deposition between the groups (Figure 4) $(\mathrm{p}=0.53$ for $\mathrm{CG}$ and $\mathrm{TG}$ at 7 days post-surgery, and $\mathrm{p}=0.077$ for $\mathrm{CG}$ and $\mathrm{TG} 13$ days post-surgery).

\section{Immunohistochemical analysis}

COX-2 expression was observed mostly in the injured area of all of the experimental groups. Seven days after the injury, the COX-2 expression was

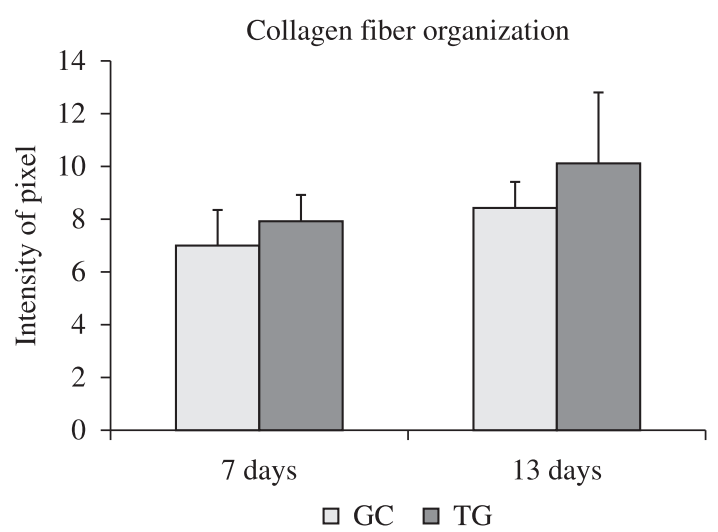

Figure 3. Qualitative analysis of the collagen assessment. (A) control group (CG) and (B) treated group (TG) at 7 days postsurgery; (C) control group (CG) and (D) treated group (TG) at 13 days post-surgery. Picrosirius stain, 40X. 

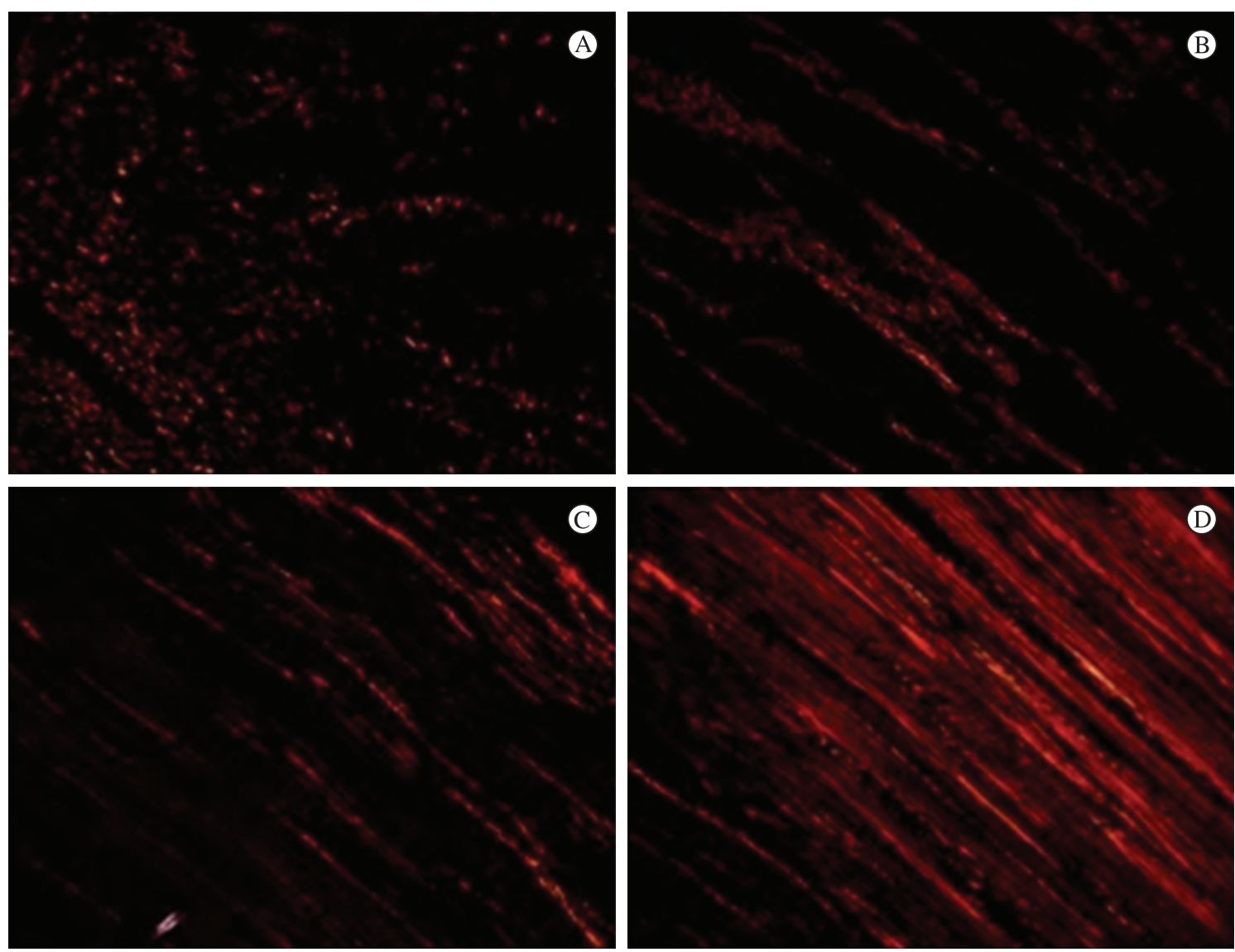

Figure 4. Means and SD of the collagen assessment. Control group (CG) and treated group (TG) for 7 and 13 days of treatments.

higher in the TG compared to the CG (Figure 5A and $5 \mathrm{~B})$. The same pattern was found in the second experimental period, with a higher expression present in the treated group (Figure 5C and 5D).

\section{- Discussion}

In this study, the effects of LIPUS on an injured TA muscle in a rat model were investigated. It was hypothesized that LIPUS would modulate the biochemical processes related to cell metabolism at the site of the injury, thereby stimulating cell proliferation and resulting in an acceleration of the healing process. The histological analysis revealed that LIPUS produced an earlier recruitment of inflammatory cells in the first time period evaluated and a better tissue organization at the site of the injury. Moreover, the treated groups presented a more organized collagen fiber deposition. Notably, LIPUS produced an upregulation of COX-2 after 7 and 13 days post-surgery.

Regarding the histopathological examination, the rats exposed to a cryolesion revealed acute extensive myofibrillary degeneration, which is related to the infiltration of neutrophil granulocytes and interstitial edema. It appears that LIPUS induces an earlier recruitment of inflammatory cells (at 7 days), which culminates in the earlier formation of new muscle cells and the acceleration of the repair process (at 13 days). Some authors have postulated that LIPUS enhances the synthesis of myogenic precursor cells and fibroblast proliferation ${ }^{2,16}$. Additionally, LIPUS appears to improve muscle extensibility and force production after contraction-induced muscle injury ${ }^{16}$. Piedade et al. ${ }^{2}$, observed that LIPUS (pulsed ultrasound, $50 \%, 1 \mathrm{MHz}$, at $0.57 \mathrm{~W} / \mathrm{cm}^{2}, 5 \mathrm{~min}$ ) induced a higher deposition of collagen fiber and stimulated the formation of myotubes in the area of injury 14 days after the lesion, which suggests a stimulatory effect of LIPUS in injured muscle tissues. In the present study, LIPUS likely stimulated fibroblast and myogenic cell proliferation, resulting in the earlier resolution of the lesion.

Moreover, the structure of the collagen fiber deposition and the fiber alignment were improved in the LIPUS-treated groups (although similar findings were not found in the quantitative collagen analysis 

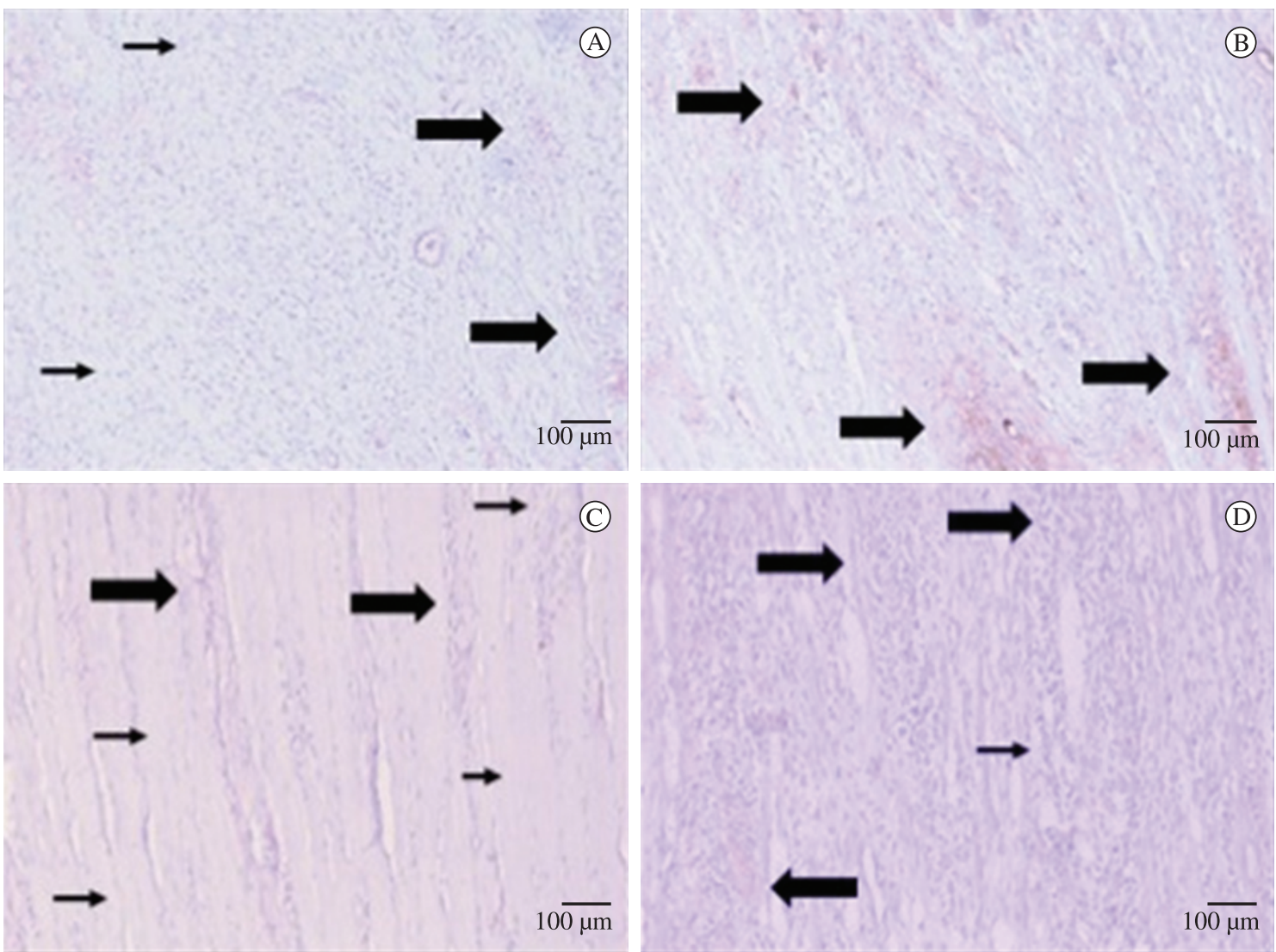

Figure 5. Immunohistochemistry: (A) Control group (CG) at 7 days; (B) Treated group (TG) at 7 days; (C) Control Group (CG) at 13 days; (D) Treated group (TG) at 13 days post-surgery. Larger arrows indicate cells with COX-2 protein immunostaining and the thin arrows indicate cells without COX-2 immunostaining. 20X.

in the experimental groups). LIPUS is known to stimulate the production of chemical mediators that activate the proliferation of fibroblasts ${ }^{2}$. This activation leads to the early accumulation of endothelial cells in the tissue as well as the promotion of collagen synthesis through the stimulation of calcium influx and a change in membrane permeability ${ }^{18}$. Collagen fibers are the main components of the basal lamina, and and the lamina basal provides a structural support for myofibers provides a structural support for myofibers ${ }^{19}$. Based on the findings of the present study, it can be suggested that LIPUS had a positive effect on collagen metabolism, stimulating collagen fiber deposition and producing improved muscle fiber organization.

The immunohistochemical analysis indicated that COX-2 expression was increased in both experimental periods. Cyclooxygenase is a key enzyme in the conversion of arachidonic acid to prostanoids or prostaglandin ${ }^{20,21}$, and cyclooxygenase is involved with many pathological processes, including inflammation, tissue repair and, ultimately, carcinogenesis ${ }^{22}$. Prostaglandins are important in the regulation of muscle protein synthesis and degradation ${ }^{20}$. In this context, the higher expression of COX-2 induced by LIPUS corroborated with the histological findings and may be related to the formation of new muscle fibers and the more organized tissue structure of the treated animals, especially at the second experimental period evaluated.

The cryolesion is a common experimental model to produce injuries in muscle tissue ${ }^{23}$. Additionally, it was observed that LIPUS, with the parameters used, had positive effects on the injured muscles. The positive effects of LIPUS on tissue repair are related to the mechanical effects of US, which produces a change in membrane permeability and stimulates the transport of second messenger substances, such as calcium, across the cell membrane ${ }^{7}$. These second messengers may then stimulate the proliferation of myogenic cells, the satellite cells, activating these cells and aiding the healing process ${ }^{7}$.

However, some limitations of our work should be noted. We investigated only short periods postinjury. It would be very interesting to develop 
experiments aimed at investigating the earlier and later modifications at different periods post-injury after LIPUS treatment. Additionally, the number of animals per group was limited to five, and more quantitative analyses should be included in future investigations, such as the quantification of inflammatory cells, the quantification of the injured area and the mechanical properties of this tissue. In spite of these limitations, the results of this work highlight the stimulatory effects of LIPUS on muscle healing. These findings provide preliminary data on the potential safety and efficacy of this therapy as an effective treatment for muscle injuries; LIPUS could allow for an earlier return to daily activities and the previous level of function, especially in athletes and workers. Our preliminary studies investigating the effects LIPUS on injured muscles in rats may also help us to design future research strategies for clinical experiments in humans.

In summary, this study demonstrates that LIPUS therapy has positive effects on tissue structure organization and the modulation of the inflammatory process at the site of the injury, improving collagen alignment and increasing COX-2 expression. Although further long-term studies and clinical trials are required, the findings of this study point to a promising utilization of such therapeutic modalities for tissue repair.

\section{References}

1. Rantanen J, Thorsson O, Wollmer P, Hurme T, Kalimo H. Effects of therapeutic ultrasound on the regeneration of skeletal myofibers after experimental muscle injury. Am. J. Sports Med. 1999 Jan-Feb;27:54-59. PMid:9934419.

2. Piedade MC, Galhardo MS, Battlehner CN, Ferreira MA, Caldini EG, De Toledo OM. Effect of ultrasound therapy on the repair of gastrocnemius muscle injury in rats. Ultrasonics. 2008;48:403-11. PMid:18384832. http:// dx.doi.org/10.1016/j.ultras.2008.01.009

3. Markert CD, Merrick MA, Kirby TE, Devor ST. Nonthermal Ultrasound and Exercise in Skeletal Muscle Regeneration. Arch Phys Med Rehabil. 2005;86:1304. PMid:16003655. http://dx.doi.org/10.1016/j.apmr.2004.12.037

4. Moyer AL, Wagner KR. Regeneration versus fibrosis in skeletal muscle. Curr Opin Rheumatol. 2011 Nov;23(6):568-73. PMid:21934499. http://dx.doi. org/10.1097/BOR.0b013e32834bac92

5. Descatha A, Roquelaure Y, Chastang JF, Evanoff B, Cyr D, Leclerc A. Description of outcomes of upper-extremity musculoskeletal disorders in workers highly exposed to repetitive work. J Hand Surg. Am. 2009;34:890-5. PMid:19410993. http://dx.doi. org/10.1016/j.jhsa.2009.02.012

6. Renno ACM, Toma RL, Feitosa SM, Fernandes K, Bossini OS, Oliveira P, et al. Comparative Effects of
Low-Intensity Pulsed Ultrasound and Low-Level Laser Therapy on Injured Skeletal Muscley. Photomed Laser Surg. 2011;29(1):5-10. PMid:21166589. http://dx.doi. org/10.1089/pho.2009.2715

7. Claes L, Willie B. The enhancement of bone regeneration by ultrasound. Prog. Biophys. Mol. Biol. 2007;93:384398. PMid:16934857. http://dx.doi.org/10.1016/j. pbiomolbio.2006.07.021

8. Dyson M, Brookes M. Stimulation of bone repair by ultrasound. Ultrasound Med Biol. 1983;2:61-6. PMid:6545743.

9. Shu B, Yang Z, Li X, Zhang LQ. Effect of different intensity pulsedultrasoundon the restoration of rat skeletalmusclecontusion. Cell Biochem Biophys. 2012;62:329-36. PMid:22068832. http://dx.doi. org/10.1007/s12013-011-9310-5

10. Kokubu T, Matsui N, Fujioka H, Tsunoda M, Mizuno K. Low intensity pulsed ultrasound exposure increases prostaglandin E2 production via the induction of cyclooxygenase- 2 mRNA in mouse osteoblasts. Biochem Biophys Res Commun. 1999 Mar 16;256(2):2847. PMid:10079177. http://dx.doi.org/10.1006/ bbrc. 1999.0318

11. Naruse K, Miyauchi A, Itoman M, Mikuni-Takagaki Y. Distinct anabolic response of osteoblast to lowintensity pulsed ultrasound. J Bone Miner Res. 2003 Feb;18(2):360-9. PMid:12568414. http://dx.doi. org/10.1359/jbmr.2003.18.2.360

12. Fávaro-Pípi E, Feitosa SM, Ribeiro DA, Bossini P, Oliveira P, Parizotto NA, et al. Comparative study of the effects of low-intensity pulsed ultrasound and low-level laser therapy on bone defects in tibias of rats. Lasers Med Sci. 2010 Sep;25(5):727-32. PMid:20521077. http://dx.doi. org/10.1007/s10103-010-0772-2

13. Sena K, Leven RM, Mazhar K, Summer DR, Virdi AS. Early gene response to low-intensity pulsed ultrasound in rat osteoblastic cells. Ultrasound Med Biol. 2005 May;31(5):703-8. PMid:15866420. http://dx.doi. org/10.1016/j.ultrasmedbio.2005.01.013

14. Silveira PC, Da Silva LA, Tromm PT, Scheffer Dda L, De Souza CT, Pinho RA. Effects of therapeutic pulsed ultrasound and dimethylsulfoxide phonophoresis on oxidative stress parameters after injury induced by eccentric exercise. Ultrasonics. 2012 Jul;52(5):6504. PMid:22326779. http://dx.doi.org/10.1016/j. ultras.2012.01.007

15. Hantes ME, Mavrodontidis NA, Zalavras CG, Karantanas AH, Karachalios T, Malizos KN. Low-intensity transosseous ultrasound accelerates osteotomy healing in a sheep fracture model. J Bone Joint Surg Am. 2004 Oct;86-A(10):2275-82. PMid:15466739.

16. Karnes JL, Burton HW. Continuous therapeutic ultrasound accelerates repair of contraction-induced skeletal muscle damage in rats. Arch Phys Med Rehabil. 2002;83:1-4. http://dx.doi.org/10.1053/apmr.2002.26254

17. Bossini PS, Rennó AC, Ribeiro DA, Fangel R, Peitl O, Zanotto ED, et al. Biosilicate ${ }^{\circledR}$ and low-level laser therapy improve bone repair in osteoporotic rats. J Tissue Eng Regen Med. 2011 Mar;5(3):229-37. PMid:20925130. http://dx.doi.org/10.1002/term.309 
18. Oliveira P, Ribeiro DA, Pipi EF, Driusso P, Parizotto NA, Renno AC. Low level laser therapy does not modulate the outcomes of a highly bioactive glass-ceramic (Biosilicate) on bone consolidation in rats. J Mater Sci Mater Med. 2010 Apr;21(4):1379-84. PMid:19943088. http://dx.doi. org/10.1007/s10856-009-3945-4

19. Carmeli E, Moas M, Reznick AZ, Coleman R. Matrix metalloproteinases and skeletal muscle: a brief review. Muscle Nerve. 2004;29:191-197. PMid:14755482. http:// dx.doi.org/10.1002/mus.10529

20. Matsumoto MA, Ferino RF, Monteleone GF, Ribeiro DA. Low-level laser therapy modulates cyclo-oxygenase-2 expression during bone repair in rats. Laser Med. Sci. 2009;24:195-201. PMid:18309458. http://dx.doi. org/10.1007/s10103-008-0544-4

21. Shen H, Sun WH, Xue QP, Wu J, Cheng YL, Fu HY, et al. Influences of Helicobacter pylori on cyclooxygenase-2 expression and prostaglandin E2 synthesis in rat gastric epithelial cells in vitro. J Gastroenterol Hepatol.
2006;21:754-758. PMid:16677165. http://dx.doi. org/10.1111/j.1440-1746.2006.04299.x

22. Shibata M, Kodani I, Osaki M, Araki K, Adachi H, Ryoke K, et al. Cyclo-oxygenase-1 and -2 expression in human oral mucosa, dysplasias and squamous cell carcinomas and their pathological significance. Oral Oncol. 2005;41:304-12. PMid:15743693. http://dx.doi. org/10.1016/j.oraloncology.2004.09.009

23. Werning A, Salvini TF, Irintchev A. Axonal sprouting and changes in fiber types after running-induced muscle damage. J Neurocytol. 1991;20:903-913. http://dx.doi. org/10.1007/BF01190468

\section{Correspondence}

Ana Claudia Muniz Rennó

Av. Ana Costa, 95, Vila Mathias

CEP 11050-240, Santos, SP, Brazil

e-mail: a.renno@unifesp.br 